\title{
Improvement of Voltage Profile and Reducing Power System Losses in Transmission System with Multiple TCSC Firing Angle Control Model with Dragonfly Algorithm
}

\author{
Mr.A.Hema Sekhar ${ }^{1}$, Dr.A.Lakshmi Devi ${ }^{2}$ \\ ${ }^{1}$ Research Scholar, Department of EEE, S.V. University College Of Engineering, Tirupati, India \\ ${ }^{2}$ Professor \& HOD, Department of EEE, S.V. University College Of Engineering, Tirupati, India
}

\begin{abstract}
Now a day the transmission lines are operated under the heavily stressed condition, hence there is risk of the consequent voltage instability. There is a multi-functional control device which can be effectively control the load flow distribution and the power transfer capability is the flexible alternating current transmission system (FACTS) Device. The FACTS device performance is depends upon its location and parameters setting. These devices have been proposed as an effective solution for controlling power flow and regulating bus voltage in electrical power systems, resulting in an increased transfer capability, low system losses, and improve stability. However to what extent the performance of FACTS devices can be brought out highly depends upon the location and the parameters of these devices. In this paper, we propose three Evolutionary Optimization Techniques, namely Genetic Algorithm (GA), Particle Swarm Optimization (PSO) and Dragonfly Algorithm (DA) to select the optimal location and the optimal parameter setting of TCSC, , firing angle of TCSC and size of the TCSC which minimize the active power losses and improves the voltage profiles in the power network, and compare their performances. To show the validity of the proposed techniques and for comparison purposes, simulations are carried out on IEEE-14 bus power system.
\end{abstract}

Keywords: Power system, Transmission system, FACTS, TCSC, Firing Angle, Genetic Algorithm, Particle Swarm Optimization \& Dragonfly Algorithm.

\section{Introduction}

Due to the ever increasing demand for the electrical power. The power network is more difficult to operate and more insecure. On the other hand, Flexible AC transmission system (FACTS) device, which can provide direct and flexible control of power transfer and are very helpful in the operation of power network. The power system performance and the power system stability can be enhanced by using FACTS devices. These devices also allow the increasing of the usable transmission capacity to its maximum thermal limits. By using FACTS devices, it is also possible to control the phase angle, firing angle, the voltage magnitude at chosen buses and /or line impedances of a transmission system. Among the FACTS devices, TCSC is one of the most effective measures for increasing the transfer capability of the transmission system, enhancing the stability, increasing voltage profile, reducing transmission losses and ameliorating the dynamic characteristics of power system. However, to achieve the over mentioned benefits, the TCSC should be properly installed in the network with appropriate parameters.

In the literature many people proposed different concepts about the placement and sizing of the TCSC, GA, PSO and DA Algorithms.

Hadi Saadat Presented Real and Reactive Power flow equations in polar form by considering two bus power system. A Jacobean matrix is then constructed and Newton Raphson method is used to solve these equations[22].Ref.[1]-[5] Papers proposed in literatures for load flow analysis with incorporated FACTS controllers in multimachine power systems from different operating conditions viewpoint. There are different load flow analysis with incorporated FACTS controllers from different operating conditions in multimachine power systems for optimal power flow control. The Newton Raphson Methods have been proposed in literatures includes for different types of Modeling of Series FACTS controllers .Sahoo et.al (2007) proposed the basic modeling of the FACTS devices for improving the system performance[6].Zhang, X.P et.al explains Jacobian Matrix of Power flow Newton Raphson algorithm and Newton Raphson strong convergence characteristics [7]. About the modeling and selection of possible locations for the installation of FACTS devices have been discussed by Gotham.D.J and G.T Heydt (1998) [8].Povh.D(2000) proposed the nice concepts of the modeling of the power systems and the impact of the FACTS devices on the transmission network [9].Modelling of the FACTS devices with various techniques with complete computer programming is proposed by Acha et.al. [10].The impact of multiple compensators in the system was proposed by Radman.G and R.S Raje [11].The important concepts of the power systems with different load flow was proposed by Stagg.G.W et.al(1968) [23]. Tong Zhu and Gamg Haung proposed(1999) the accurate points of the buses which were suitable for the FACTS 
devices installation [12].P.Kessal and H. Glavitsch(1986) proposed increase the transmission capability, improvement of stability by installing FACTS devices in transmission network [13].Hingorani N.G et.al presented about FACTS devices, which are a family of high-speed electronic devices, which can significantly increase the power system performance by delivering or absorbing real and/or reactive power [24]. Hugo Ambriz-Perez et.al presented a novel power flow model for the Thyristor Controlled Series Compensator (TCSC).The model takes the form of a firing angle-dependant, nodal admittance matrix that is then incorporated in an existing Power flow algorithm [14]. Ref [15-17] papers proposed on the placement of the TCSC by using genetic algorithm concepts. There are various stochastic search algorithms which have proved to be very efficient in solving complex power system problems. PSO is a novel population based method which utilizes the swarm intelligence generated by the cooperation and competition between the particle in a swarm and has emerged as a useful tool for engineering optimization.[18-20]. S.Meerjaali (2015) proposed a new approach of optimization by using Dragon fly algorithm [21].

In this paper, the optimal location for placement of FACTS device has been formulated as a problem, and is solved using a new heuristic algorithm called the Dragonfly Algorithm. The Dragonfly Algorithm is used for finding out the optimal locations and parameter settings of Thyristor Controlled Series Compensator (TCSC) devices, to achieve minimum transmission line losses in the system. The Dragonfly Algorithm results are compared with the results of the Genetic Algorithm (GA) and the Particle Swarm Optimization (PSO) techniques.

\section{Power Flow Analysis}

Power-flow or load-flow studies are important for planning future expansion of power systems as well as in determining the best operation of existing systems. The principal information obtained from the powerflow study is the magnitude and phase angle of the voltage at each bus, and the real and reactive power flowing in each line.

The power mismatch equations $\Delta \mathrm{P}$ and $\Delta \mathrm{Q}$ are expanded around a base point $(\theta(0), \mathrm{V}(0))$ and, hence, the power flow Newton-Raphson algorithm is expressed by the following relationship

$$
\left[\begin{array}{l}
\Delta P \\
\Delta Q
\end{array}\right]=\left[\begin{array}{ll}
\frac{\partial P}{\partial \theta} & \frac{\partial P}{\partial V} V \\
\frac{\partial Q}{\partial \theta} & \frac{\partial Q}{\partial V} V
\end{array}\right]\left[\begin{array}{c}
\Delta \theta \\
\frac{\Delta V}{V}
\end{array}\right]
$$

Where

$\Delta P$ is the change of real power at the bus.

$\Delta Q$ is the change of reactive power at the bus.

$\Delta \mathrm{V}$ is the change in voltage at the bus

$\Delta \theta$ is the change in angle at the bus

\section{Series Compensation}

FACTS controllers can be broadly divided into four categories, which include series controllers, shunt controllers, combined series-series controllers, and combined series-shunt controllers.

In series compensation, capacitors are connected in series with the transmission lines. This reduces the transfer reactance between buses to which the line is connected, increases the maximum power that can be transmitted, and reduces the effective reactive power losses. Although series capacitors are not usually implemented for voltage control, they do contribute to improving the system voltage and reactive power balance. The reactive power produced by a series capacitor increases with transferred power of the transmission line. Examples of such controllers are Static Synchronous Series Compensator (SSSC), Thyristor-Switched Series Capacitor (TSSC), Thyristor-Controlled Series Reactor (TCSR), Thyristor-Controlled Series Capacitor (TSSC). They can be effectively used to control current and power flow in the system and to damp oscillations of the system.

\section{Thyristor Controlled Series Capacitor (TCSC)}

The basic conceptual TCSC [14] module constitutes of three components- a capacitor bank C, a bypass inductor $\mathrm{L}$ and the bidirectional thyristors SCR1 and SCR2 as shown in Fig.1. In Fig.1 $\mathrm{I}_{\mathrm{c}}$ and $\mathrm{I}_{\mathrm{L}}$ represents instantaneous values of the capacitor bank and inductor respectively $\mathrm{I}_{\text {line }}$ is the instantaneous current of the controlled transmission line, $\mathrm{V}$ is the instantaneous voltage across the TCSC. Also installed across the capacitor is a circuit breaker, $\mathrm{CB}$, for controlling its insertion in the line. In addition, the CB bypasses the capacitor if severe fault or equipment-malfunction events occur. A current-limiting inductor, $L d$, is incorporated in the 
circuit to restrict both the magnitude and the frequency of the capacitor current during the capacitor-bypass operation.

An actual TCSC system usually comprises a cascaded combination of many such TCSC modules, together with a fixed-series capacitor, $C F$. This fixed series capacitor is provided primarily to minimize costs.

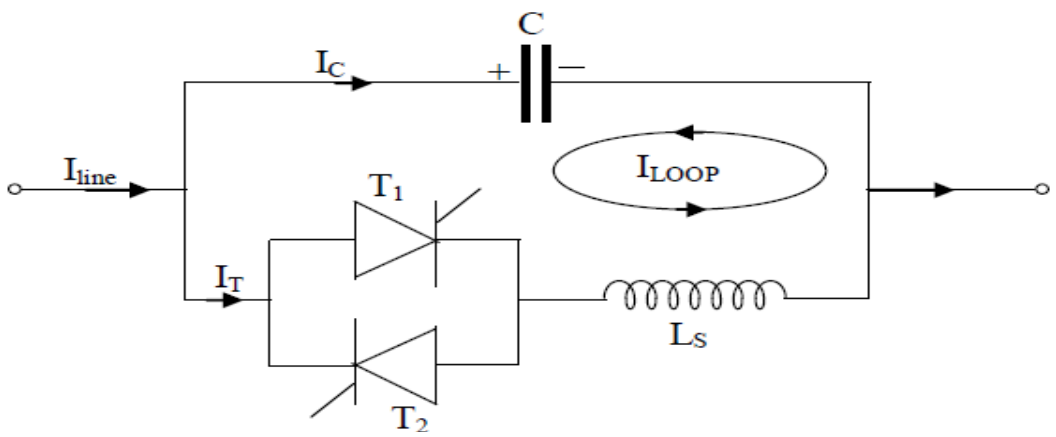

Fig. 1: A Basic Module of TCSC

\section{Operation of The TCSC (Firing Angle Power Flow Model)}

The equivalent circuit of TCSC for firing angle model is shown in Fig. 2, which consists of an antiparallel connection of thyristors and the combination of inductor and capacitor. The thyristor combination is fired at various angles to obtain the required power flow in the line. It has been in use for many years to increase line power transfer as well as to enhance system stability. The firing angles $(\alpha)$ of the thyristors are controlled to adjust the TCSC reactance in accordance with a system control algorithm, normally in response to some system parameter variations. The TCSC can be controlled to work in capacitive zone. According to the operating principle of the TCSC, it can control the active power flow for the line $l$ (between bus- $f$ and bus- $t$ where the TCSC is installed). The computation of the firing angle is carried out. However, such calculation involves an iterative solution since the TCSC reactance and firing angle are nonlinearly related. The fundamental frequency of $\mathrm{X}_{\mathrm{TCSC}(1)}$ equivalent reactance as a function of the TCSC firing angle $\alpha$ is shown in fig. 2.

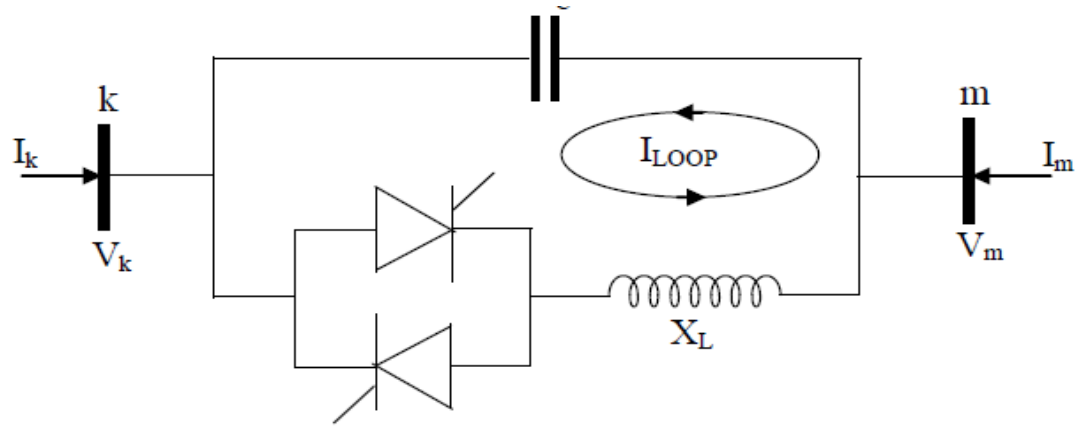

Fig. 2: fundamental frequency equivalent reactance XTCSC (1) of the TCSC module

$$
X_{T C S C(1)}=-X_{c}+C_{1}\{2(\pi-\alpha)+\sin [2(\pi-\alpha)]\}-C_{2} \cos ^{2}(\pi-\alpha)\{\omega \tan [\omega(\pi-\alpha)]-\tan (\pi-\alpha)\}
$$

Where

$$
\begin{aligned}
C_{1} & =\frac{X_{c} X_{L c}}{\pi} \\
C_{2} & =\frac{4 X_{L C}^{2}}{X_{L} \pi} \\
X_{L C} & =\frac{X_{c} X_{L}}{X_{c}-X_{L}}
\end{aligned}
$$




$$
\omega=\left(\frac{X_{c}}{X_{L}}\right)^{\frac{1}{2}}
$$

TCSC active and reactive power equations at bus $\mathrm{k}$ are

$$
\begin{aligned}
& P_{k}=V_{k} V_{m} B_{k m} \sin \left(\theta_{k}-\theta_{m}\right) \\
& Q_{k}=-V_{k}^{2} B_{k k}-V_{k} V_{m} B_{k m} \cos \left(\theta_{k}-\theta_{m}\right)
\end{aligned}
$$

Where

$$
B_{k k}=B_{k m}=B_{T \csc (1)}
$$

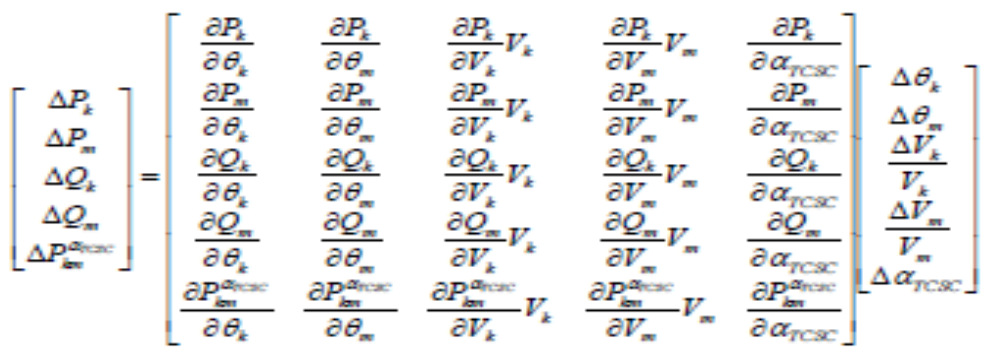

Where $\Delta P_{k m}^{\alpha_{T C S C}}=P_{k m}^{r e g}-P_{k m}^{\alpha_{T \mathrm{csc}}}$ is the active power mismatch for TCSC module. $\Delta \alpha_{T \mathrm{csc}}$ is the incremental change in the TCSC firing angle.

\section{Genetic Algorithm}

The goal of the optimization is to find the best location of a given number of FACTS devices in accordance with a defined criterion. A configuration of FACTS devices is defined with three parameters: the location of the devices, their types and their values. In order to take into account the three aforementioned parameters in the optimization, a particular coding is developed. An individual is represented with three strings of length, where is the number of devices to locate optimally. The first string corresponds to the individual represents the values of the devices. It can take discrete values contained between 0 and 1;0 corresponding to the minimum value that the device can take and 1 to the maximum.

Genetic Algorithms were developed based on the evolutionary theories proposed by Darwin in the 19th century. These algorithms are based on the Darwinian principle that the elements that are most suitable to their environment have the highest probability of surviving and they are able to transmit their characteristics to their offspring.

Genetic Algorithm is one of the most famous heuristic optimization technique which is based on natural selection and genetics [15] - [17].It is usually used to get the near optimal solution. In each generation a new set of chromosomes with an improved fitness is generated by using the following genetic operators. i) Selection ii) Cross Over iii) Mutation The initialization of chromosome structure of GA uses the rating and location of FACTS devices. i) Selection: In this method tournament selection is used for the selection. In this method tournament size chosen is 4. ii) Cross Over: It selects genes from the parent chromosomes and generates a new offspring. Cross over is the process of taking two parents and generating from them an offspring. iii) Mutation : It is performed after the cross over. It is used to prevent falling of all solutions into the local optimum. In the case of binary encoding a few randomly chosen bits from 1 to 0 or from 0 to 1 .With the firing angles the size of the TCSC is calculated. The Objective of selection of optimal value of firing angle at required location is minimization of losses

\section{Particle Swarm Optimization}

Mr. Kennedy and Mr. Eberhart first introduced the PSO in the year of 1995 [18] - [20] PSO has its roots in artificial life and social psychology as well as in engineering and computer science. It utilizes a population of individuals, called particles, which fly through the problem hyperspace with some given initial velocities. In each iteration the velocities of the particles are stochastically adjusted considering the historical best position of the particles and their neighborhood best position; where these positions are determined according to some predefined fitness function. Then, the movement of each particle naturally evolves to an optimal or at least near-optimal solution. In PSO algorithm, the particles fly in a multidimensional search space. During the flight each particle adjust its position according its own experience, and the experience of the neighboring particles, making use of the best position encountered by itself and its neighbors

In general, maximum number of iterations for termination of the search process and inertia weights is set according to the following equation: 


$$
\begin{aligned}
\mathrm{w} & =\mathrm{w}_{\max }-\frac{\mathrm{w}_{\max }-\mathrm{w}_{\min }}{i t e r_{\text {mac }}} \cdot \text { iter } \\
\mathrm{v}^{\left(t^{+1)}\right.} & =w i \cdot{ }^{(t)}+c 1 \cdot r 1 \cdot\left(x g b e s t^{(t)}-x i^{(t)}+c 2 \cdot r 2 \cdot\left(\text { xipbest }^{(t)}-x i^{(t)}\right)\right. \\
\mathrm{x}^{\left(t^{+1)}\right.} & =x i^{\left(t^{(}\right)}+v i^{\left(t^{+1)}\right.}
\end{aligned}
$$

The particles are initialized by the location of the buses and firing angles. The selection of the buses and firing angles is carried out by minimization of the losses.

\section{Dragonfly Algorithm (DA)}

Dragonflies [21] are considered as small predators that hunt almost all other small insects in nature. Nymph dragonflies also predate on other marine insects and even small fishes. The interesting fact about dragonflies is their unique and rare swarming behaviour. Dragonflies swarm for only two purposes: hunting and migration. The former is called static (feeding) swarm, and the latter is called dynamic (migratory) swarm.

The main objective of any swarm is survival, so all of the individuals should be attracted towards food sources and distracted outward enemies. Considering these two behaviours, there are five main factors in position updating of individuals in swarms as shown in Fig. 3.

According to Reynolds, the behaviour of swarms follows three primitive principles :

- Separation, which refers to the static collision avoidance of the individuals from other individuals in the neighbourhood.

- Alignment, which indicates velocity matching of individuals to that of other individuals in neighbourhood.

- Cohesion, which refers to the tendency of individuals towards the centre of the mass of the neighbourhood.

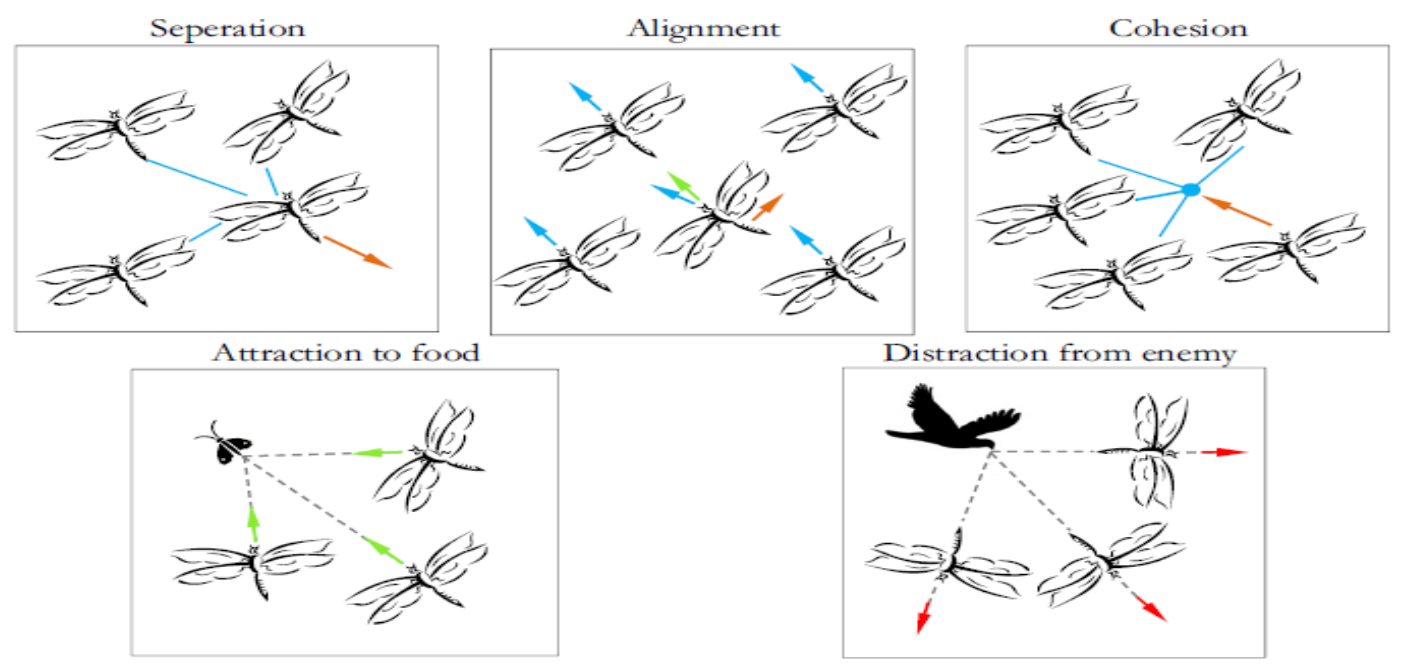

Fig. 3: Primitive behaviour of Dragonflies

Each of these behaviours is mathematically modeled as follows:

The separation is calculated as follows

$$
S_{i}=-\sum_{j=1}^{N} X-X_{j}
$$

where $\mathrm{X}$ is the position of the current individual,

$\mathrm{Xj}$ shows the position $\mathrm{j}$-th neighbouring individual, and

$\mathrm{N}$ is the number of neighbouring individuals.

Alignment is calculated as follows:

$$
A_{j}=\frac{\sum_{j=1}^{N} V_{j}}{N}
$$

where $\mathrm{Vj}$ shows the velocity of $\mathrm{j}$-th neighbouring individual. 
The cohesion is calculated as follows:

$C_{j}=\frac{\sum_{j=1}^{N} X_{j}}{N}-X$

where $\mathrm{X}$ is the position of the current individual, $\mathrm{N}$ is the number of neighbourhoods, and $\mathrm{Xj}$ shows the position $\mathrm{j}$-th neighbouring individual

Attraction towards a food source is calculated as follows:

$F_{i}=X^{+}-X$

where $\mathrm{X}$ is the position of the current individual, and $\mathrm{X}^{+}$shows the position of the food source.

Distraction outwards an enemy is calculated as follows:

$E_{i}=X^{-}+X$

where $\mathrm{X}$ is the position of the current individual, and $X^{-}$shows the position of the enemy.

$\Delta X_{t+1}=\left(s S_{i}+c C_{i}+f F_{i}+a A_{i}+e E_{i}\right)+w \Delta X_{t}$

where s shows the separation weight, $\mathrm{Si}$ indicates the separation of the $\mathrm{i}$-th individual, a is the alignment weight,

$\mathrm{A}$ is the alignment of $\mathrm{i}$-th individual, $\mathrm{c}$ indicates the cohesion weight, $\mathrm{Ci}$ is the cohesion of the $\mathrm{i}$-th individual, $\mathrm{f}$ is the food factor, $\mathrm{Fi}$ is the food source of the $\mathrm{i}$-th individual, $\mathrm{e}$ is the enemy factor, Ei is the position of enemy of the ith individual, $w$ is the inertia weight, and $t$ is the iteration counter.After calculating the step vector, the position vectors are calculated as follows:

$X_{t+1}=X_{t}+\Delta X_{t+1}$

To improve the randomness, stochastic behaviour, and exploration of the artificial dragonflies, they are required to fly around the search space using a random walk (Levy flight) when there is no neighbouring solutions. In this case, the position of dragonflies is updated using the following equation:

$X_{t+1}=X_{t}+\operatorname{Levy}(x) X_{t}$

The dragon flies are populated with the bus numbers of the system and the firing angles to the switching device of the TCSC. The objective to finalize the optimal location with the suitable firing angle of the TCSC is the minimizing of the losses.

\section{Test Case}

The proposed method is used to analyze the standard IEEE 14 bus transmission network. The important parameters that can be determined by proposed methods are power flows, voltage profile of the buses, real and reactive power losses.

1. IEEE 14 Bus System

The single line diagram of IEEE 14 bus system is shown fig. 4 


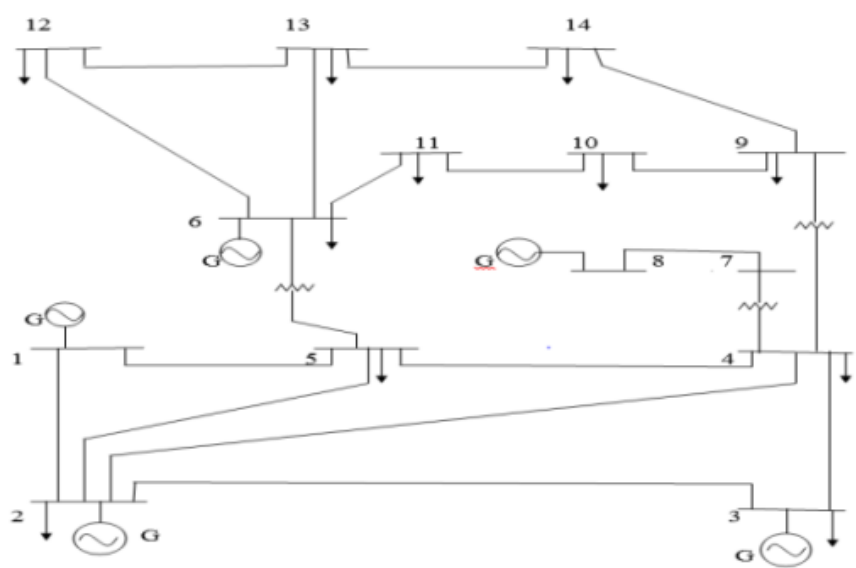

Fig. 4: Single line diagram of IEEE 14 bus system

\section{Single TCSC Placement}

The placement of single TCSC by using different optimizing techniques such as GA, PSO and DA is implemented on IEEE 14 bus system. By placing TCSC at different locations of the transmission network the real and re active power losses are reduced. With the reference of the table.1.The losses are greatly reduced by dragonfly algorithm (DA),by placing the single TCSC. The real and reactive power losses without TCSC are $9.682 \mathrm{MW}$ and 50.04 MVar but in case of dragonfly algorithm (DA) the real and reactive power losses are reduced to $9.222 \mathrm{MW}$ and $49.08 \mathrm{MVar}$. The voltage profile, branch real and reactive power losses without placing of TCSC and with the placing of single TCSC are shown in the figures 5,6,7,8 and 9 respectively.

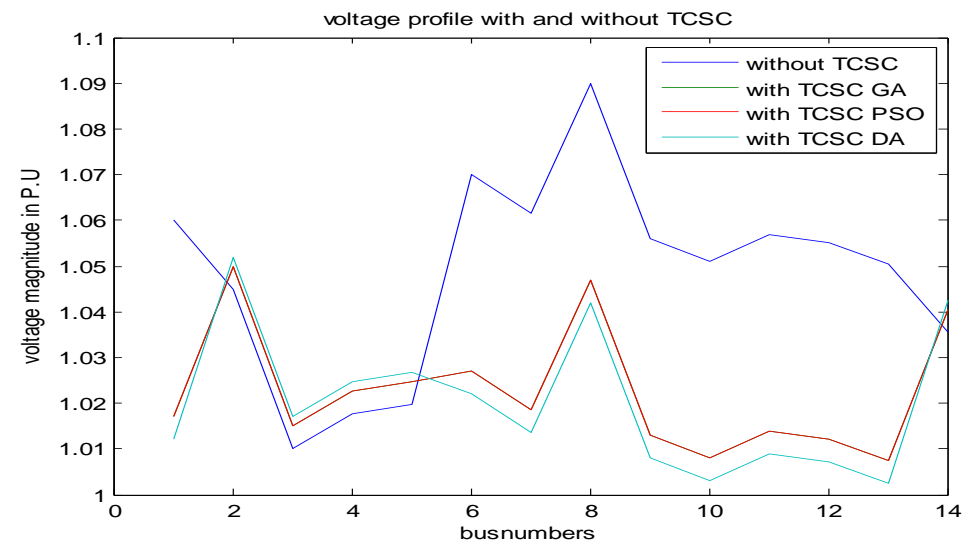

Fig. 5 : Comparative Voltage Profile for IEEE 14 bus system with TCSC

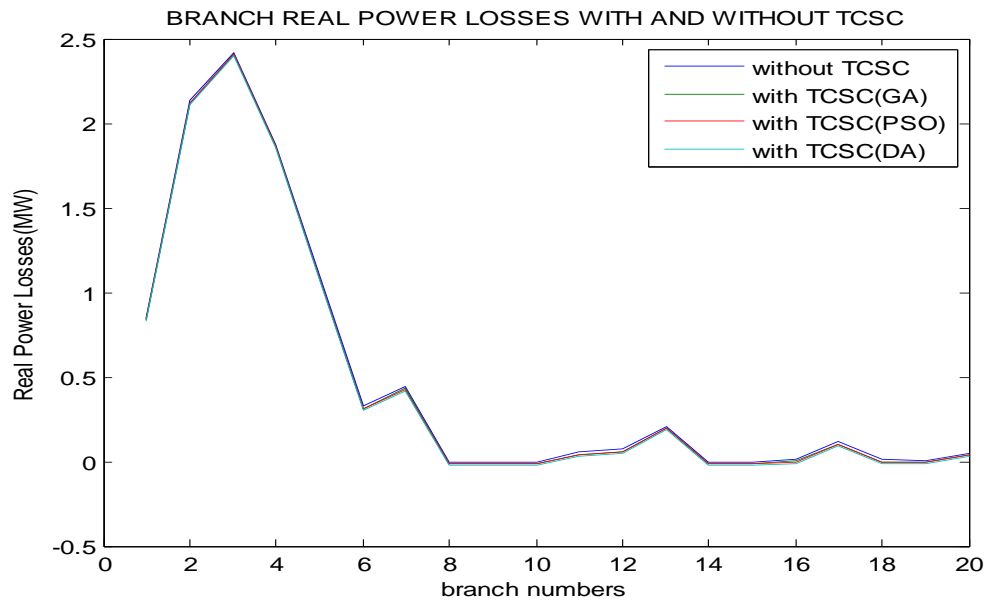

Fig. 6:Branch Real power losses of IEEE 14 bus with and without TCSC 


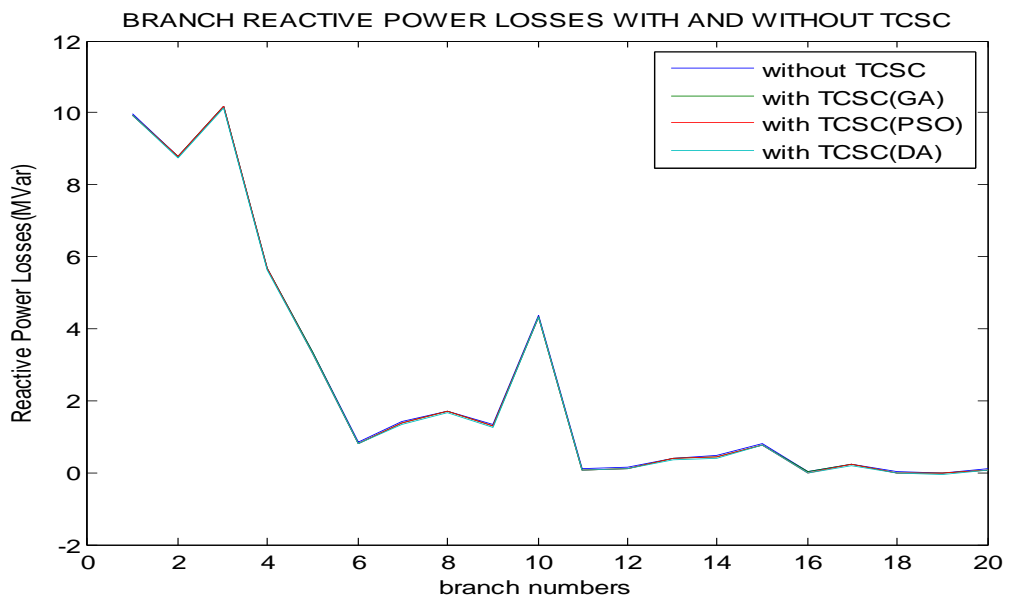

Fig. 7: Branch Reactive power losses of IEEE 14 bus with and without TCSC

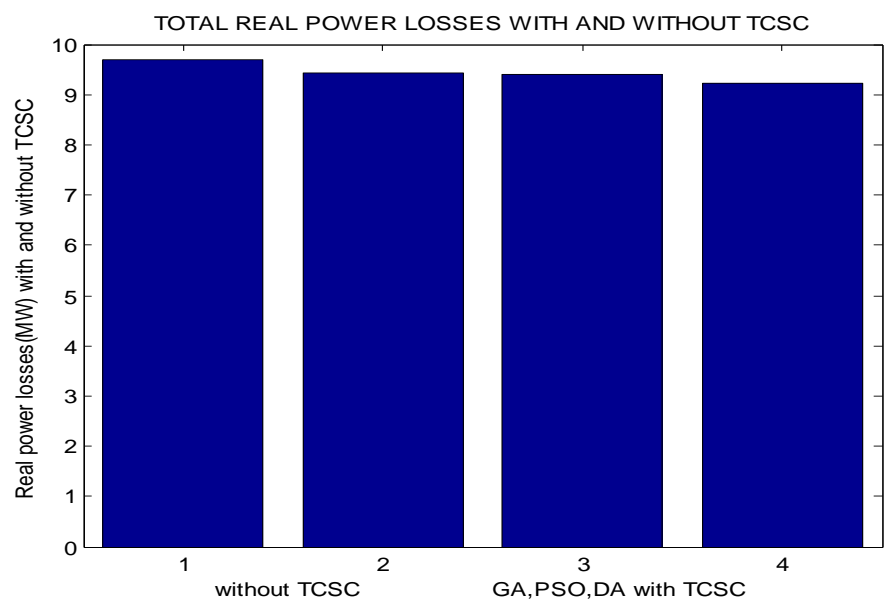

Fig. 8 : Comparative analysis of Real power losses of IEEE 14 bus with and without TCSC

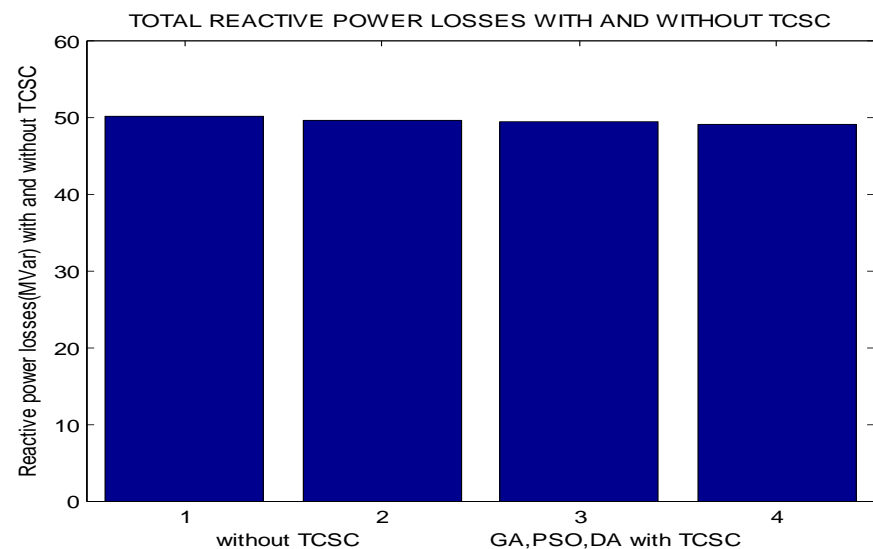

Fig.9: Comparative analysis of Reactive power losses of IEEE 14 bus with and without TCSC

\section{Placement of Two TCSC's}

With the inclusion of two TCSC's in the bus system then the power flows are further improved and losses further are reduced which is shown in the table 1 . The voltage profile, branch real and reactive power losses without placing of TCSC and with the placing of two TCSC are shown in the figures 10, 11.12,13 and 14 respectively. 


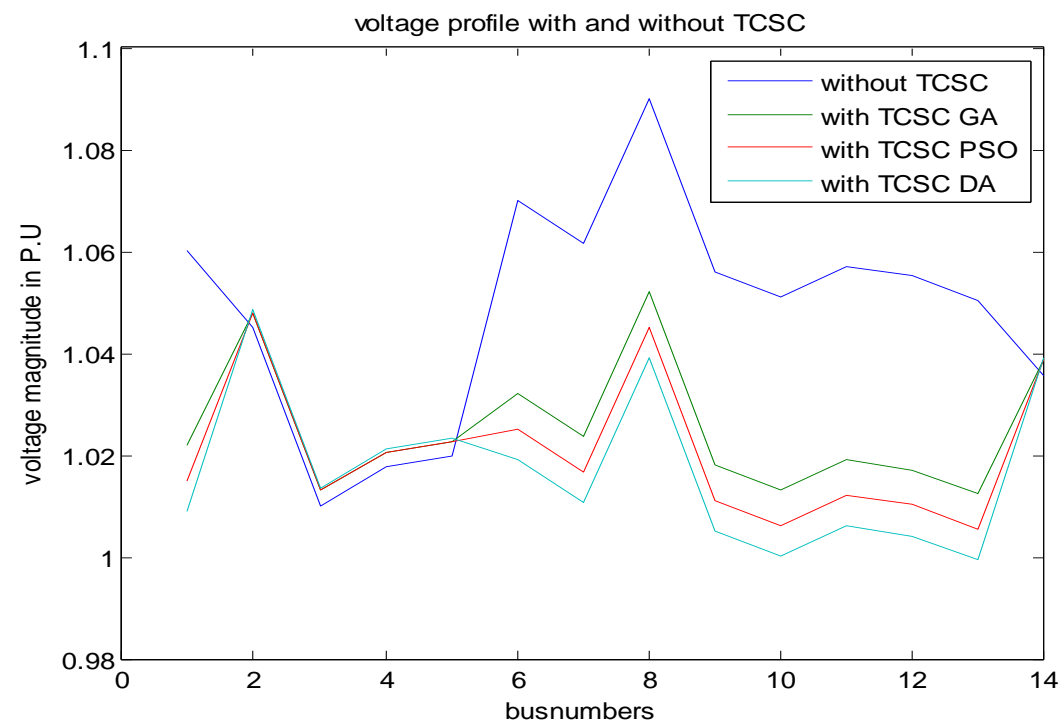

Fig.10: Voltage profile for IEEE 14 bus system with two TCSC's

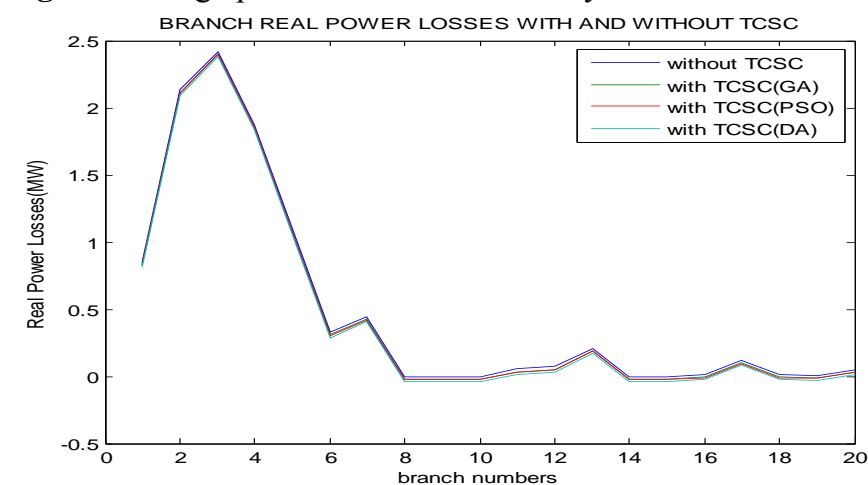

Fig.11: Comparative analysis of Real power losses of IEEE 14 bus with and without two TCSC's

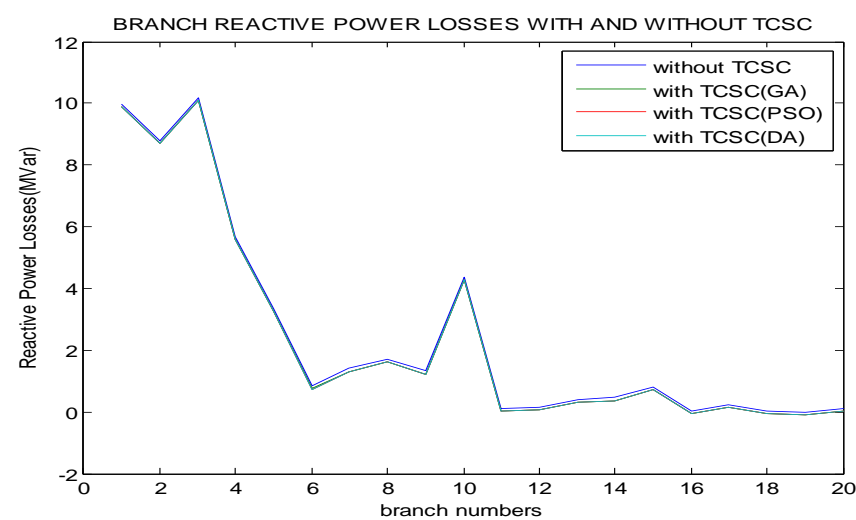

Fig. 12: Comparative analyses of Reactive power losses of IEEE 14 bus with and without two TCSC's 


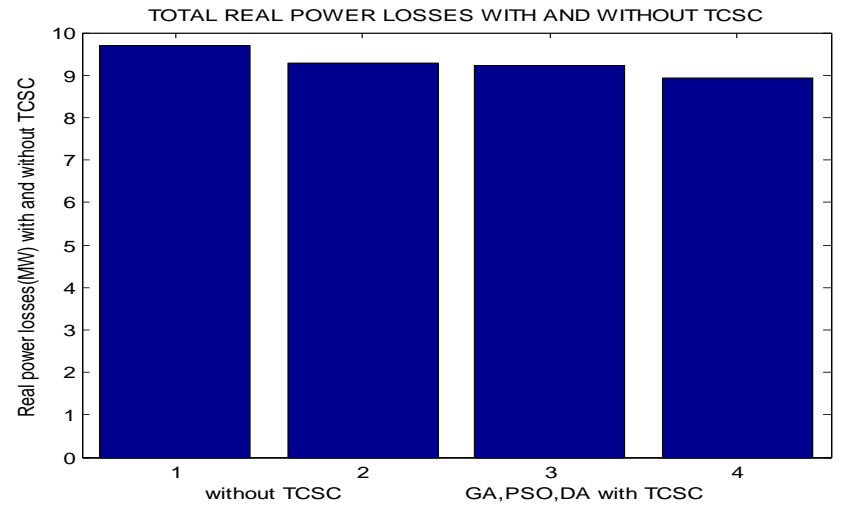

Fig. 13: Comparative analyses of Real power losses of IEEE 14 bus with two TCSC's

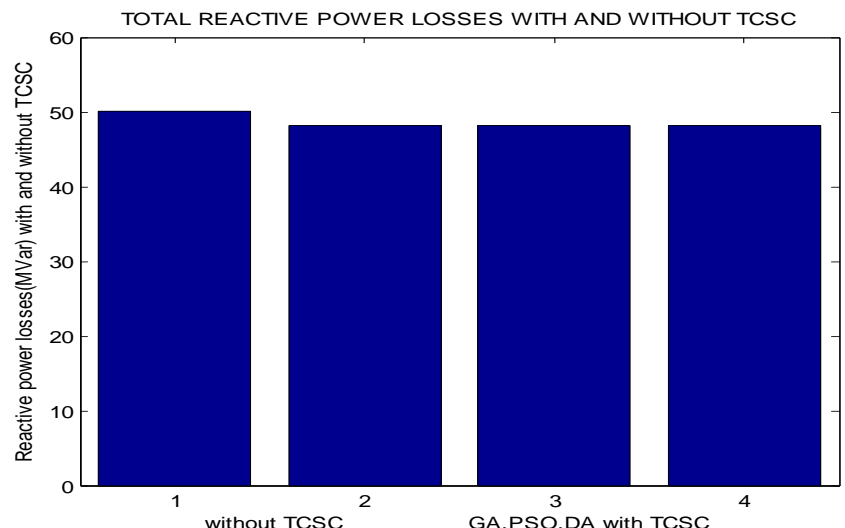

Fig. 14: Comparative analyses of Reactive power losses of IEEE 14 bus with two TCSC's

Table 1: Comparative System Parameters of IEEE 14 bus with and without TCSC by using GA, PSO And DA

\begin{tabular}{|c|c|c|c|c|c|c|c|}
\hline Parameters & $\begin{array}{l}\text { Without } \\
\text { TCSC }\end{array}$ & $\begin{array}{l}\text { With Single } \\
\text { TCSC(GA) }\end{array}$ & $\begin{array}{l}\text { With Two } \\
\text { TCSC(GA) }\end{array}$ & $\begin{array}{l}\text { With Single } \\
\text { TCSC(PSO) }\end{array}$ & $\begin{array}{l}\text { With Two } \\
\text { TCSCs } \\
\text { (PSO) }\end{array}$ & $\begin{array}{l}\text { With } \\
\text { Single } \\
\text { TCSC(DA) }\end{array}$ & $\begin{array}{l}\text { With Two } \\
\text { TCSCs } \\
\text { (DA) }\end{array}$ \\
\hline $\begin{array}{l}\text { Minimum } \\
\text { Voltage(p.u) }\end{array}$ & $\begin{array}{l}1.01 \text { at } \\
\text { bus } 3\end{array}$ & $\begin{array}{l}1.004 \text { at } \\
\text { bus } 13\end{array}$ & $\begin{array}{l}1.016 \quad \text { at } \\
\text { bus } 10\end{array}$ & $\begin{array}{l}1.0052 \text { at } \\
\text { bus } 13\end{array}$ & $\begin{array}{ll}1.018 & \text { at } \\
\text { bus } 10 & \\
\end{array}$ & $\begin{array}{l}1.0062 \text { at } \\
\text { bus } 13\end{array}$ & $\begin{array}{l}1.02 \\
\text { bus } 10\end{array}$ \\
\hline $\begin{array}{l}\text { Maximum } \\
\text { Voltage(p.u) }\end{array}$ & $\begin{array}{l}1.09 \text { at } \\
\text { bus } 8\end{array}$ & $\begin{array}{l}1.05 \text { at bus } \\
2\end{array}$ & $\begin{array}{l}1.042 \text { at } \\
\text { bus } 2\end{array}$ & 1.05 at bus 2 & $\begin{array}{ll}1.048 & \text { at } \\
\text { bus 2 } & \\
\end{array}$ & $\begin{array}{ll}1.048 & \text { at } \\
\text { bus 2 } & \\
\end{array}$ & $\begin{array}{l}1.046 \text { at } \\
\text { bus } 2\end{array}$ \\
\hline $\begin{array}{l}\text { Real power } \\
\text { losses(Mw) }\end{array}$ & 9.682 & 9.422 & 9.282 & 9.402 & 9.222 & 9.222 & 8.922 \\
\hline $\begin{array}{l}\text { Reactive } \\
\text { power } \\
\text { losses(Mvar) }\end{array}$ & 50.04 & 49.48 & 48.2 & 49.44 & 48.14 & 49.08 & 48.08 \\
\hline $\begin{array}{l}\text { Location of } \\
\text { TCSC }\end{array}$ & ---------- & 7-9 line & $\begin{array}{l}\text { 6-11 line } \\
6-13 \text { line }\end{array}$ & 6-13 line & $\begin{array}{l}\text { 6-12 line } \\
7-9 \text { line }\end{array}$ & $9-14$ line & $\begin{array}{l}\text { 3-4 line } \\
6-11 \text { line }\end{array}$ \\
\hline $\begin{array}{l}\text { TCSC 1firing } \\
\text { angle(deg) }\end{array}$ & |--------- & 132.3 & 136.3 & 131.8 & 136.3 & 132.6 & 134.3 \\
\hline $\begin{array}{l}\text { TCSC2 firing } \\
\text { angle(deg) }\end{array}$ & --------- & ----- & 127.3 & ------ & 126.3 & ------ & 122.6 \\
\hline $\begin{array}{l}\text { Size } \\
\text { TCSC1 } \\
\text { (Kvar) }\end{array}$ & $\begin{array}{l}--------- \\
-\end{array}$ & 2.38 & 1.410 & 2.36 & 1.42 & 2.33 & 1.38 \\
\hline $\begin{array}{ll}\text { Size } & \text { of } \\
\text { TCSC2 } \\
\text { (Kvar) }\end{array}$ & ---------- & ----- & 0.983 & ----- & 0.973 & ----- & 0.963 \\
\hline
\end{tabular}

From the above table, it is shown that without TCSC the Real and Reactive power losses are 9.682 MW and 50.04 MVar.In case of Genetic Algorithm for placing single TCSC the losses are Reduced i.e Real and 
Reactive power losses are 9.422 MW and 49.48 MVar and for two TCSC's 9.282 MW \& 48.2 MVar.By applying Particle Swarm Optimization (PSO) for placing single TCSC the Real and Reactive power losses are further reduced to $9.402 \mathrm{MW}$ and 49.44 MVar and by using two TCSC's the losses are $9.222 \mathrm{MW}$ and 48.14 MVar.By applying Proposed method i.e Dragonfly Algorithm (DA) for placing single TCSC, the Real and Reactive power losses are most further reduced to 9.222 MW and 49.08 MVar and by using two TCSC's the losses are reduced to $8.922 \mathrm{MW}$ and $48.08 \mathrm{MVar}$, So,The DA method gives better losses reduction as compared to GA and PSO.

\section{Conclusion}

The Firing Angle Model of Thyristor controlled series capacitor (TCSC) using GA,PSO and DA methods has been implemented on IEEE 14 test system to investigate the performance of power transmission line in absence of TCSC and presence of single and double TCSC devices. In this paper, Dragonfly Algorithm has been proposed to analyze firing angle model of TCSC .The results obtained for above bus system using proposed method with and without TCSC compared and observations reveal that the Real and Reactive power losses are less with TCSC. The obtained results are supportive, and show that the TCSC is one of the most effective series compensation devices that can significantly increase the voltage profile of the system. GA and PSO methods were also presented to analyze the firing angle model of TCSC and the results are compared with proposed method which is shown in tables 1 . From this we can conclude that when the single and two TCSC's are placed in the IEEE 14 bus system, The Dragonfly algorithm gives better voltage profile improvement and better reduction in transmission line losses. Also the results indicate that the Dragonfly algorithm was an easy to use and best optimization technique compared with the Genetic algorithm (GA) and the Particle Swarm Optimization (PSO).

\section{Journal Papers:}

\section{References}

[1]. Abdel-Moamen, M.A. Narayana Prasad Padhy, “ Power Flow Control and Transmission Loss Minimization Model with TCSC for Practical Power Networks", Power Engineering Society General Meeting, 2003, IEEE, Vol.2, 13-17 July 2003, pp 880-884.

[2]. Venegas T., Fuerte-Esquivel, C.R. "Steady-State Modelling Of Thyrister Controlled Series Compensator For Phase Domain Load Flow Analysis Of Electric Network”, Electric Utility Deregulation and Restructuring and Power Technologies, 2000. Proceedings. DRPT 2000. International Conference, 4-7 April 2000 Page(s):191 - 196.

[3]. Kumar G.R.; Rao, R.K.; Ram, S.S.T., Power Flow Control and Transmission Loss Minimization model with TCSC and SVC for Improving System Stability and Security” Industrial and Information Systems, 2008. ICIIS 2008. IEEE Region 10 and the Third international Conference on 8-10 Dec. 2008 Page(s): 1 - 5.

[4]. M.O. Hassan, S. J. Cheng, and Z. A. Zakaria, "Steady-state Modeling of Static Synchronous Compensator and Thyristor Controlled Series Compensator for Power Flow Analysis,” Information Technology Journal, Vol. 8, Issue 3, 2009, pp. $347-353$.

[5]. Xiao-Ping Zhang, 'Advanced Modeling of the Multi control Functional Static Synchronous Series Compensator (SSSC) in Newton Power Flow”, Power Systems, IEEE Transactions on Volume 18, Issue 4, Nov. 2003 Page(s):1410 - 1416.

[6]. Sahoo, A.K., S.S. Dash, and T. Thyagarajan. 2007. Modeling of STATCOM and UPFC for Power System Steady State Operation and Control. IET-UK International Conference on Information and Communication Technology in Electrical Sciences (ICTES 2007). (http://digital-library.theiet.org.sci-hub.cc/content/conferences/10.1049/ic_20070656)

[7]. Zhang, X.P., C. Rehtanz, and B. Pal. 2006. Flexible AC Transmission Systems: Modelling and Control. Springer Verlag: Berlin, Germany

[8]. Gotham, D.J. and G.T. Heydt. 1998. Power Flow Control and Power Flow Studies for Systems with FACTS Devices. IEEE Trans. Power Syst. 13(1): 60-66.

[9]. Povh, D. 2000. Modeling of FACTS in Power System Studies. Proc. IEEE Power Eng. Soc. Winter Meeting. 2:1435-1439.

[10]. Acha, E., C.R. Fuerte-Esquivel, H. Ambriz-Pe'rez, and C. Angeles-Camacho. 2004. FACTS: Modelling and Simulation in Power Networks. John Wiley and Sons: West Sussex, UK. (Power flow has been optimized by placement of the FACTS controllers)

[11]. Radman, G. and R.S. Raje. 2007. Power Flow Model/Calculation for Power Systems with Multiple FACTS Controllers. Electric Power Systems Research. 77:1521-1531.

[12]. Tong Zhu, Garng Huang, Find the accurate point of voltage collapse in real-time. in Proc. of the 21st IEEE International Conference on Power Industry Computer Applications, PICA '99, Santa Clara, CA, May 1999

[13]. P.Kessal H.Glavitsch ,Estimating the voltage stability of a power system IEEE .Transaction on Power Delivary .vol.PWRD1.N3.july 1986

[14]. Ambriz-Pérez H., Acha E., Fuerte-Esquivel CR "TCSC-firing angle model for optimal power flow solutions using Newton's method", International Journal of Electrical Power \& Energy Systems, Volume 28, Issue 2, February 2006, Pages 77-85.

[15]. Abouzar samini and Peyman naderi 2012,"'A New Method for Optimal Placement of TCSC based on sensitive Analysis for congestion Management, Smart grid and Renewable Energy Feb-2012.

[16]. L. J. Cai, I. Erlich and G. Stamtsis, "Optimal Choice and Allocation of FACTS Devices in Deregulated Electricity Market Using Genetic Algorithms," in Proceeding of the IEEE Power Systems Conference and Exposition, October 2004, Vol. 1, pp. 201-207

[17]. Stéphane Gerbex, Rachid Cherkaoui, and Alain J. Germond, "Optimal Location of Multi-Type FACTS Devices in a Power System by Means of Genetic Algorithms," IEEE Transactions on Power Systems, Vol. 16, No. 3, August 2001, pp. 537-544.

[18]. J.Kennedy and R Eberhart, "Particle Swarm optimization," proc. IEEE Int. Conf.Neural Networks, Vol 4, pp 1942-1948, 1995.

[19]. D. Mondal, A. Chakrabarti , A. Sengupta, ”Optimal placement and parameter setting of SVC and TCSC using PSO to mitigate small signal stability problem”, ELSEVIER, Electrical Power and Energy Systems 42 (2012) 334-340.

[20]. G.I.Rashed,H.I.Shaheen,S.J.Cheng,"Optimum location and parameter setting of TCSC by both Genetic Algorithm and Partival swarm Optimization”, 2007 second international conference on Industrial Electronics and Applications, 1141-1147

[21]. Syedali Merjalili "Dragonfly algorithm: a new meta-heuristic optimization technique for solving single-objective, discrete, and multi-objective problems", Spinger Neural Comput \& Application 


\section{Books:}

[22]. Power System Analysis - Hadi Saadat, Tata MC Graw Hill, Edition 2002

[23]. Stagg, G.W. and A.H. Ei-Abiad. 1968. Computer Methods in Power Systems Analysis. McGraw-Hill: New York, NY.

[24]. Hingorani, N.G. and L. Gyugyi. 2000. Understanding FACTS: Concepts and Technology of Flexible AC Transmission Systems. Wiley-IEEE Press: New York, NY. ISBN: 0-7803-3464-7. 